\title{
Research of overall performance of polymeric sprinkler of coolers
}

\author{
Boev Evgeni Vladimirovich \\ Chair of «General chemical technology» \\ Ufa State Petroleum Technological University, Branch in \\ the Sterlitamak \\ Sterlitamak, Russia \\ 9196011116@mail.ru \\ Boeva Nina Ivanovna \\ Chair of «Humanities» \\ Ufa State Petroleum Technological University, Branch in \\ the Sterlitamak \\ Sterlitamak, Russia
}

\author{
Daminev Rustem Rifovich \\ Chair of «General chemical technology» \\ Ufa State Petroleum Technological University, Branch in \\ the Sterlitamak \\ Sterlitamak, Russia \\ daminew@mail.ru \\ Karimov Oleg Khasanovich \\ Chair of «General chemical technology» \\ Ufa State Petroleum Technological University, Branch in \\ the Sterlitamak \\ Sterlitamak, Russia
}

\begin{abstract}
Observance of temperature condition of any production is carried out by means of the systems of reverse water supply equipped most often with fans and cooling towers. In this article, the design of the drop and film sprinkler of coolers and results of a research of efficiency of his work is described.
\end{abstract}

Keywords - Reverse water supply, the cooler, the nozzle device, a heat mass exchange, cooling.

\section{INTRODUCTION}

The systems of reverse water supply are one of the most important elements of a technological complex of the enterprises of many industries: chemical, oil processing, petrochemical, machine building, metallurgical, etc. Productivity of processing equipment, quality and prime cost of a product, a specific consumption of raw materials and the electric power depend on quality and overall performance of systems of reverse water supply [1].

The systems of industrial water supply consist of a complex of the interconnected constructions - water intakes, pump stations, installations for cleaning and the improvement of quality of water regulating and spare capacities, coolers of water and the parting network of pipelines. Depending on appointment and local conditions, some of the listed constructions in system can be absent.

The basic purpose of water on production is as follows:

- water can be the heat carrier when cooling a product through a wall or at protection of designs of the unit against destruction (burn-through). In both cases water in the course of her use heats up and practically does not become soiled;

- water can be environment, absorbing and transporting the mechanical or dissolved impurity (at a sink, enrichment and purification of raw materials or a product). In the course of use, this water becomes soiled with the mechanical and dissolved impurity;

- water can be solvent of the reagents used at preparation of environments for floatation enrichment of coal, ore or nonmetallic minerals, etc. In this case, as well as by chemical preparation of water for receiving from her steam, water turns into technological water or solution. A quantity of water goes to a drain together with waste of reagents and other impurity;

- water can be also used in a complex - to be environment, absorbing and transporting the mechanical and dissolved impurity, and at the same time to serve as the heat carrier (the product cooler), for example, at purification of gas, etc. [2].

At the industrial enterprises, this or that type of use of water is prevailing. For example, at thermal power plants of $85 \%$ of the general consumption of water it is used for cooling of air, oil and condensation of the fulfilled steam; about $12 \%$ on hydraulic transportation of ashes (if as fuel coal is used); $3 \%$ - on steam preparation. At the plants of ferrous and nonferrous metallurgy, the main amount of water is spent for cooling of structural elements of furnaces, rolling mills and cars, a quantity - on hydraulic transportation of scale. At the enterprises of the mining industry water is the environment absorbing and transporting mechanical impurity (breeds).

In general, by all types of the industry of $70-75 \%$ of the general consumption of water, it is used mainly as the heat carrier.

Requirements imposed to temperature of reverse water by various industrial enterprises are dictated by technological process and operational properties of the equipment. At the choice like coolers for ensuring this temperature, it is necessary to consider a possibility of pollution of water production products in a water reverse cycle.

The enterprises of heat power branch consume two thirds of the fresh water, which is taken away for industrial needs from water supply sources at its greatest expenditure for cooling of processing equipment $(96 \%)$. However the water recirculation coefficient in branch below an average on the industry also makes about $60 \%$ because of remained from previous years at many power enterprises of direct-flow systems of water supply. So, from 144 thermal power plants 
on the direct-flow systems of water supply work with the rated volume of $215 \mathrm{GW} 45$ and on reverse 99.

Excess of temperature of reverse water from regulated leads to decrease in development of production (quite often up to $15 \%$ ) and to deterioration in its quality. At the same time, water temperature, returned in a reverse cycle, often exceeds the regulated temperature, and the enterprises for maintenance of the required temperature condition resort to undesirable reception - "refreshing" of system of reverse water supply at which they raise to $10 \%$ and more dumping from the system of warm water at simultaneous increase in a consumption of make-up fresh water from a natural source $[3,4]$.

In the systems of reverse water supply water is cooled by means of transfer of heat to atmospheric air. A part of heat is transferred owing to superficial evaporation of water (water evaporates which by diffusion is transferred to the atmosphere), other part - owing to a difference of water temperatures and air, i.e. due to heat conductivity and convection. Very small amount of heat is taken away from water by a radiation more that in thermal balance usually isn't considered. At the same time inflow of heat to the cooled water from solar radiation takes place.

For obtaining the required temperature the fulfilled reverse water directly or after preliminary cleaning of pollution before its new use is cooled in special constructions: ponds coolers, the sprinkling pools and coolers (tower or fan).

In most cases the efficiency of process of cooling is defined by nozzle devices (sprinklers) capable to provide the necessary surface of contact of phases at minimum possible aero - and hydrodynamic resistance.

Now in the industry as sprinklers of the cooler the designs executed from a tree or asbestos cement are still used. The main shortcomings of these sprinklers are big weight per unit area, the small surface of contact, high coefficient of aerodynamic resistance and small service life. Wood is sensitive to chemical and biological influence, and levels of sprinklers can't be thinner than $10 \mathrm{~mm}$ because of buckling and destruction of wood as a result of washing away by water of lignin from its (delignifikation). As a result of the last for communication of cages in wood there is only a cellulose and she becomes fragile. Process of a delignifikation goes more intensively at high $\mathrm{pH}$ values and considerable content in water of active chlorine [1]. So, at increase in $\mathrm{pH}$ from 5 to 9 intensity of destruction of a larch and an oak increases by 2-3 times, and pines and fir-trees - at 10-16 times [5].

The efficiency of process of cooling of water in coolers is defined by design features of nozzle devices (sprinklers) providing the necessary surface of contact of phases at minimum aero - and hydrodynamic resistance.

Now the big variety of designs of sprinklers of coolers, however is known in view of the fact that in the industry the tendency of replacement of products from traditional materials (wood, asbestos cement) on polymeric products with various sizes and forms of section, demand for which increases both on internal, and in the world market, is observed, there is a need of creation of new highly effective and technological designs of sprinklers of coolers from polymeric materials.
Depending on character of the prevailing surface of cooling sprinklers can be:

- film;

- drop and film.

Each type of the irrigating device can have very various designs of separate elements and the sizes.

In the course of creation of new designs of sprinklers of coolers it is necessary to be based on the analysis of the known designs for what we will consider the principle of their work, design features and we will generalize the main data on this problem which are available in modern scientific and technical and patent literature. At the same time irrigating devices in each case have to conform to technical requirements, the shown state standards concerning the cooling ability and cost of the cooler in which they will be used.

The value of losses of a pressure at the movement of air in the sprinkler also is the integral indicator of his work as it characterizes operational costs of the cooler. It is necessary to consider also some other indicators - durability, wearability of material, durability and mass of the sprinkler, ease of installation, availability of repairs and surveys and also maintenance in the cooled water of the weighed substances and aggressive impurity.

\section{RESULTS}

So in the branch of Ufa state petroleum technological university in Sterlitamak, a series of designs of polymeric drop and film sprinklers of coolers, one of which is represented in figure 1 , is developed.

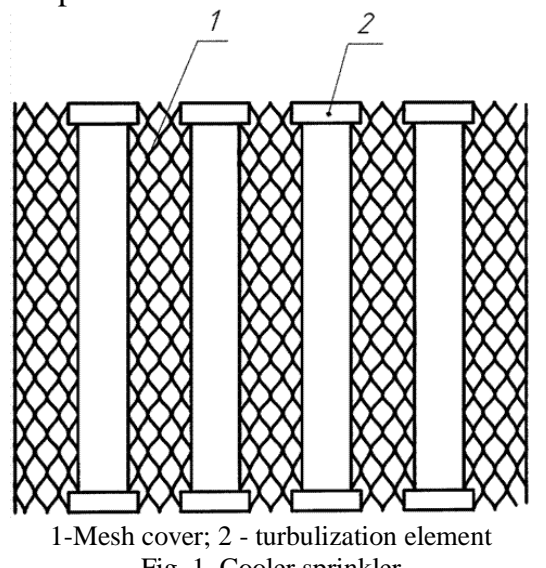

Fig. 1. Cooler sprinkler

The sprinkler of the cooler is made in the form of the module of layers of the polymeric mesh covers 1 executed cylindrical, placed in all vertical slices in parallel each other and between mesh covers from both end faces turbulization elements 2 of irregular shape, as shown in figure 2 are placed.

The sprinkler of coolers works as follows.

Reverse water is pumped on the sprinkler of coolers and under the influence of mass forces passes through it, flowing down a thin stream on polymeric mesh covers. Turbulization elements swirl the ascending air stream, intensifying thereby process of a heatmass exchange that promotes increase in time of contact of drops of water with an air stream. 


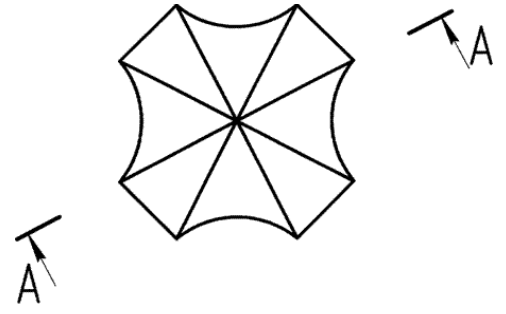

Fig. 2. Turbulization element

Hydroaero thermal tests of irrigating devices were carried out for the purpose of determination of volume coefficients warm and mass transfer on the basis of a complex of the obtained data which includes parameters of the water passing through installation (an expense, temperature of hot and chilled water) and air (an expense, temperature and relative humidity on an entrance, barometric pressure).

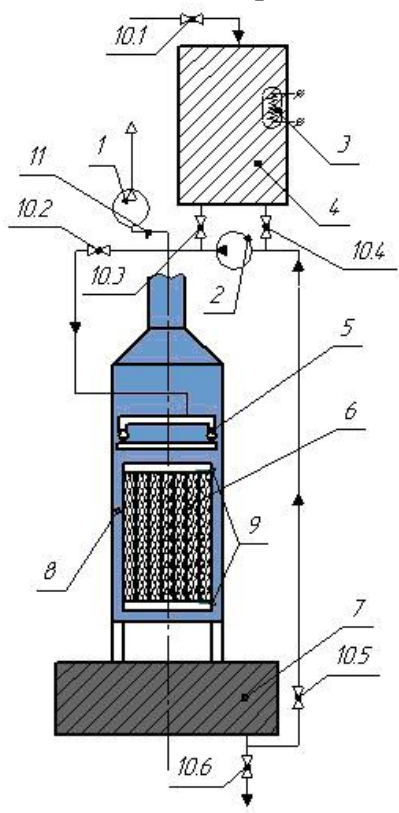

1 fan; 2 - pump; 3 - heating devices; 4 - container with hot water; 5 water distribution system; 6 - the studied cooler sprinkler; 7 - capacity with chilled water; 8 - mine vertical (installation case); 9 - measuring devices; 10.1-10.6 - shutoff valves; 11 - anemometer.

Fig. 3. Experimental installation

Experimental installation consists of the following basic elements (figure 3).

1. The mine vertical with a general height of $4,5 \mathrm{~m}$ is collected from a metalwork of various profile and serves for installation of all layout elements of installation and modeling of the counterflow scheme of cooling of water in the cooler. Sidewalls of the mine are made of sheet polystyrene. The face of the mine is made of plexiglas that allows to conduct visual observation and to control process of distribution (redistribution) of water in elements of irrigating devices. The mine consists of the top section where the water distribution system is placed; working section for installation of elements of examinees of irrigating devices up to $1,5 \mathrm{~m}$ high, $0,5 \mathrm{~m}$ wide and $0,5 \mathrm{~m}$ in depth (the area of irrigation of $0,25 \mathrm{sq} . \mathrm{m}$ ); the lower section for collecting chilled water and giving of an air stream. The working section and section of placement of water distribution devices have corresponding technological "doors" which allow carrying out installation and scheduled maintenance freely. "Doors" are densely closed when carrying out tests. If necessary, the special assembly site joins working section of the mine. For transition from the rectangular section of the top section to an air duct, the confusor which provides alignment of speed of an air stream on mine section serves.

2. The water bringing system of installation serves for the organization of a water reverse cycle, installation of primary converters of an expense and temperature sensors. It consists of the container with hot water, the circulation pulser, heating devices, pressure head pipelines, shutoff valves, the crane of additional water and capacity with chilled water. On the water bringing pipeline the frequency converter of energy allowing to regulate rotation frequency эл is installed. The engine and the centrifugal pump given by it, thereby smoothly to change a consumption of the water pumped on the studied cooler sprinkler.

3. The water distribution system of installation - pressure head type. She serves for uniform distribution of water on the area of irrigation of working section. Water is brought on a pipe to the water distribution lattice consisting of four main pipelines having a number of water outlets.

4. The water-collecting system of installation is intended for collecting the water cooled in working section, branch in the container with hot water.

5. The water-heating system is intended for heating of reverse water and maintenance of its temperature at the necessary level. The water-heating system consists of three 4 $\mathrm{kW}$ water heaters which are in capacity volume for hot water. She allows to establish and support the necessary level of heating of water, to conduct manual and automatic control of water heating process.

6. The airtaking-away system serves for creation of the directed ascending air stream in working section of installation. For measurement of a consumption of air in the taking-away air duct the diaphragm is established, and smooth change of a consumption of air is carried out by means of the shiber gate installed in an air duct.

Experimental installation works as follows:

By means of the circulation pump water is pumped in capacity for hot water. Water heats up to necessary temperature and moves on the pressure head pipeline, passing electro-acoustic converters of an expense in the water distribution system of the mine of experimental installation. The water distribution system rather evenly distributes a water stream on the area of irrigation of working section of the mine where the examinee a fragment of the irrigating device is established. The counter air flow in the mine of installation is created by the centrifugal fan and the system of air ducts. Air is sucked in through the airentrance windows located on all sides of the mine resembles through working section with the sprinkler, water distribution system and on air ducts is taken out in the atmosphere. Height of airentrance windows is 
limited to the lower part of working section of the mine and the top part of a water-collecting tank. In volume of the tested irrigating device there are most intensive processes warm and a mass exchange between the flowing-down hot water and the stream of cold air moving towards. The water cooled in the sprinkler flows down in the water-collecting tank installed in the lower section of the mine of experimental installation from where the pump moves in the pressure head bringing pipeline and a tank for hot water again - the water reverse cycle of hydroaero thermal tests becomes isolated.

In practice, final results of determination of coefficients warm and mass transfer can be presented in the form of the dependence connecting two dimensionless complexes number of evaporation $K_{E V}$ and a relative consumption of air $\lambda[6]$.

The dependence of number of evaporation on a relative consumption of air is most precisely approximated in a sedate look:

$$
K_{E V}=A_{p} \lambda^{m}
$$

where $A p$ - the empirical coefficient characterizing design features of the sprinkler; $\lambda$ - relation of a mass consumption of air to a water consumption; $m$ - the coefficient reflecting influence of a mass consumption of air on cooling of water in this design of the sprinkler.

$$
\lambda=\frac{G_{A}}{G_{W}},
$$

where $G_{A}$ and $G_{W}$ - a specific mass consumption of air and liquid, $\mathrm{kg} /\left(\mathrm{m}^{2} \mathrm{~s}\right)$.

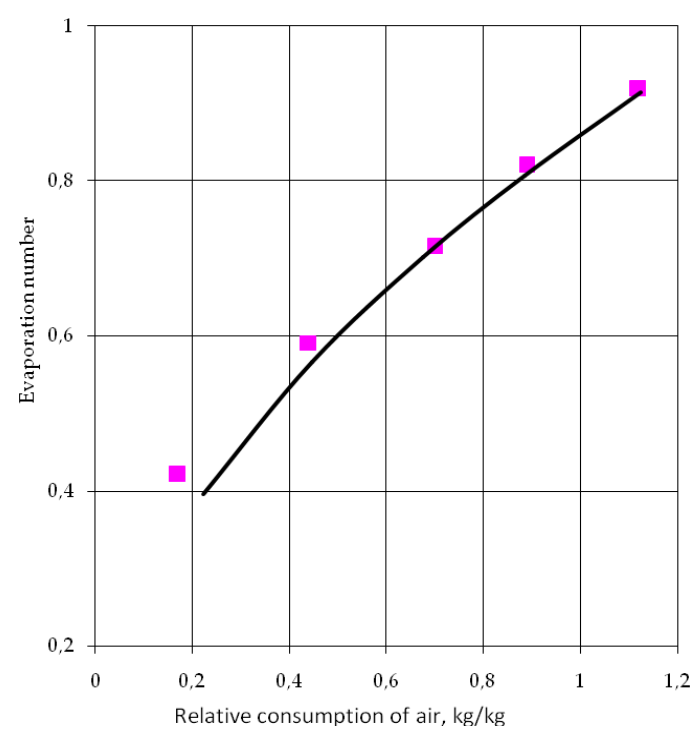

Fig. 4. Dependence of number of evaporation on a relative consumption of air

On the conducted pilot studies of characteristics of blocks of sprinklers from polymeric mesh covers the following empirical dependences for determination of their main technical characteristics have been received:

$$
\Delta P=\left[K_{1}+K_{2} \cdot q\right] \frac{\rho_{A} \cdot w^{2}}{2 g \cdot \rho_{W}}
$$

where $\Delta \mathrm{P}-$ losses of total pressure in the sprinkler, $\mathrm{m}$ of water column; K1, K2 - the functions of speed of an air stream depending on diameter of mesh covers; $w$ - speed of an air stream, $\mathrm{m} / \mathrm{s} ; \mathrm{q}$ - density of irrigation, $\mathrm{m}^{3} /\left(\mathrm{m}^{2} \mathrm{~s}\right) ; \mathrm{g}$ - acceleration of gravity, $\mathrm{m} / \mathrm{c}^{2} ; \rho_{\mathrm{A}}$ - density of air, $\mathrm{kg} / \mathrm{m}^{3} ; \rho_{\mathrm{W}}$ - density of water, $\mathrm{kg} / \mathrm{m}^{3}$.

Calculation of coefficient of aerodynamic resistance of the sprinkler was made on Veysbakh's formula:

$$
\zeta_{o p}=\frac{2 g \Delta P \rho_{W}}{\omega_{2}^{2} \rho_{A}}
$$

where $g$ - acceleration of gravity, $\mathrm{m} / \mathrm{c}^{2} ; \Delta P$ - losses of a pressure, mm w.g.; $\rho_{W}$ - density of water, $\mathrm{kg} / \mathrm{m}^{3} ; \omega_{2}$ - speed of an air stream, $\mathrm{m} / \mathrm{s} ; \rho_{A}$ - density of external air, $\mathrm{kg} / \mathrm{m}^{3}$.

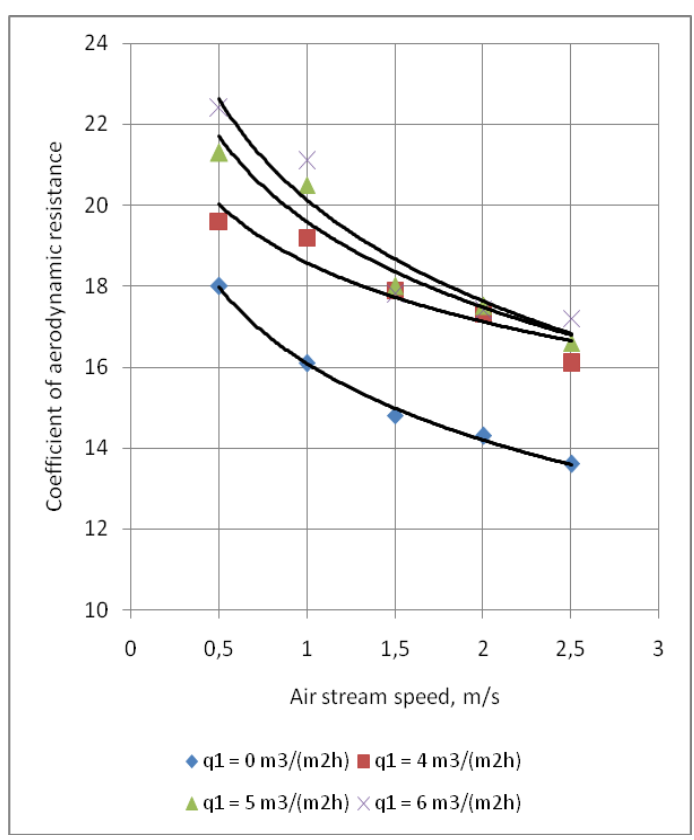

Fig. 5. Dependence of coefficient of aerodynamic resistance on speed $\zeta_{o p}$ of an air stream $\omega_{2}$ at the different density of irrigation of q1

For definition of hydroaero thermal characteristics and the cooling ability of the sprinkler were measured:

- speed of the movement of air in the free section of the cooler over the sprinkler, $\omega, \mathrm{m} / \mathrm{s}$;

- density of irrigation, $q_{W}, \mathrm{~m}^{3} / \mathrm{m}^{2} \mathrm{~h}$; ${ }^{0} \mathrm{C}$;

\footnotetext{
- temperature of hot water on an entrance to the cooler, $t_{1}$,
} 
- temperature of chilled water at the exit from the cooler, $t_{2},{ }^{0} \mathrm{C}$;

- barometric pressure, $P_{B}, \mathrm{~mm} \mathrm{Hg}$;

- air temperature on the dry thermometer, $\vartheta,{ }^{0} \mathrm{C}$;

- air temperature on the moistened thermometer, $\tau,{ }^{0} \mathrm{C}$.

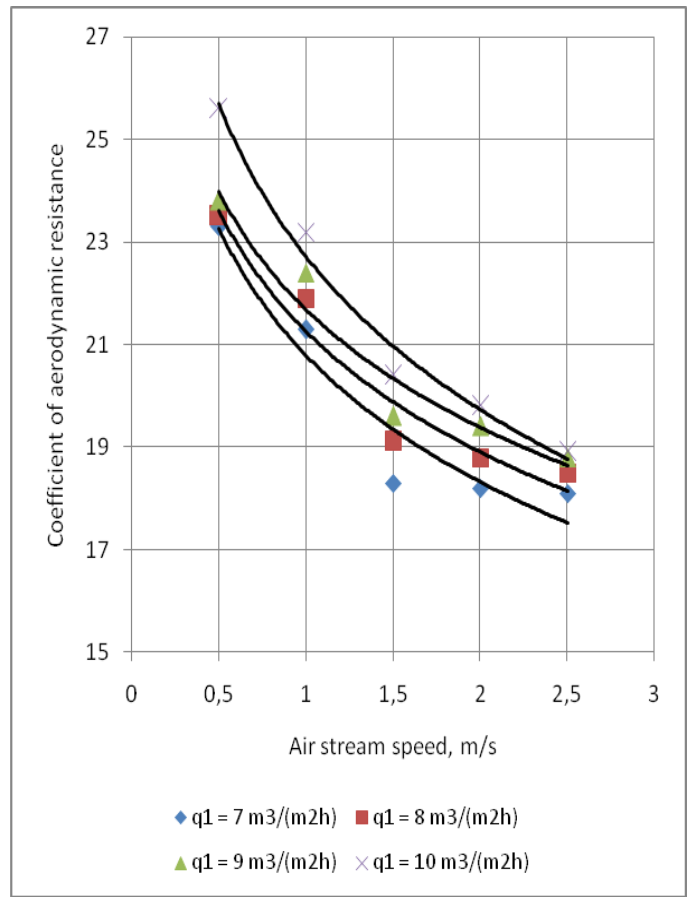

Fig. 6. Dependence of coefficient of aerodynamic resistance on speed $\zeta_{o p}$ of an air stream $\omega_{2}$ at the different density of irrigation of q1

Besides, 2 more sizes are measured: the area of the sprinkler in respect of $\mathrm{F}$, sq.m and height of the sprinkler $\mathrm{h}, \mathrm{m}$.

Processing of results of measurements was made by a formula:

$$
M e=\frac{\Delta t \cdot c_{W}}{K \cdot \Delta i_{A V}}
$$

where

$$
\Delta t=t_{1}-t_{2}
$$

$\mathrm{K}$ was counted as function of value. $t_{2}$.

$$
K=1-0,00173 t_{2} \text {. }
$$

Calculation of an average difference of heat contents of air $\Delta i_{C P}$ by L.D. Berman's method was made by means of a formula:

$$
\Delta i_{C P}=\frac{\left(i_{1}{ }^{\prime \prime}-i_{2}\right)-\left(i_{2}{ }^{\prime \prime}-i_{1}\right)}{\ln \frac{i_{1}{ }^{\prime \prime}-i_{2}-\delta_{i}{ }^{\prime \prime}}{i_{2}{ }^{\prime \prime}-i_{1}-\delta_{i}{ }^{\prime \prime}}} .
$$

On the basis of the conducted pilot hydroaero thermal researches (at the density of irrigation of $\mathrm{q}=4-10 \mathrm{~m}^{3} /\left(\mathrm{m}^{2}\right.$ • $\mathrm{h})$ ), the main hydroaero thermal characteristics of sprinklers of coolers from polymeric mesh covers are defined and also empirical dependences of difference of temperatures on the speed of an air stream are received.

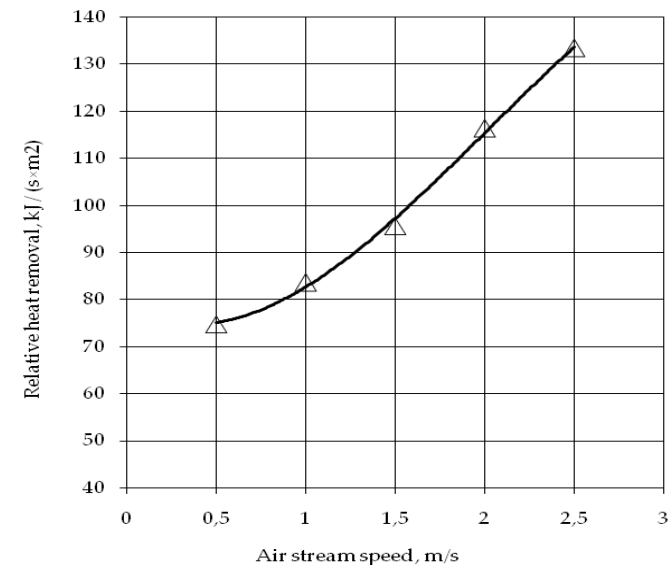

Fig. 7. Dependence of relative heat removal of $\mathrm{Q} / \mathrm{F}, \mathrm{kJ} /\left(\mathrm{s} \cdot \mathrm{m}^{2}\right)$ from the speed of an air stream of $\mathrm{w}, \mathrm{m} / \mathrm{s}$

\section{CONCLUSION}

On the basis of the conducted researches and, based on the analysis of the known designs, the design by drop infusion the film sprinkler of coolers on the basis of polymeric mesh covers and the elements is offered. The dependence of number of evaporation on a relative consumption of air for the presented design is investigated. The empirical dependence of coefficient of aerodynamic resistance on the speed of an air stream at the different density of irrigation allowing one to calculate most precisely the load of the fan and to define optimum operating modes of the cooler is received [7-8].

\section{References}

[1] V.S. Ponomarenko, Yu.I. Arefyev, Coolers of the industrial and power enterprises: Handbook, M.: Energoatomizdat, 1998.

[2] A.F. Shabalin, Reverse water supply of the industrial enterprises, M.: Stroyizdat, 1972.

[3] E.V. Boev, S.P. Ivanov, V.G. Afanasenko, E.A. Nikolaev, "Polymeric drop-film sprinklers for cooling towers", Chemical and Petroleum Engineering, Vol. 45, № 7-8, pp. 454-459, 2009.

[4] E.V. Boev, S.P. Ivanov, A.V. Boev, "Design development of a polymeric atmospheric film-type sprayer for cooling towers", Chemical and Petroleum Engineering, Vol.43, № 9-10, pp. 572-574, 2007.

[5] D.I. Kucherenko, V.A. Gladkov, Reverse water supply, M.: Stroyizdat: 1980.

[6] R.E. Gelfand, B.L. Sverdlin, V.I. Shishov "Laboratory researches of irrigating devices and the recommendation about their application at repairs, technical re-equipment and design of new coolers", New in the Russian power, Vol. 2, pp. 39-47, 2004.

[7] S.P. Ivanov, I.G. Ibragimov, K.E. Bondar', O.S. Ivanov, "Increasing the efficiency of heat and mass exchange processes in the water rotation cycles of industrial enterprises" Chemical and Petroleum Engineering, Vol. 50, № 11-12, pp. 806-810, 2015.

[8] F.Sh. Khafizov, V.G. Afanasenko, I.F. Khafizov, A.Sh. Khaibrakhmanov, "Main treatment ways of manufacturing water on the local plants”, Russian Journal of Applied Chemistry. Vol. 81, № 9, pp. 1697-1698, 2008. 